\title{
Optimal pressing strength and time for capillary refilling time
}

\author{
Rui Kawaguchi ${ }^{1}$, Taka-aki Nakada ${ }^{1 *}$, Taku Oshima ${ }^{1}$, Masayoshi Shinozaki ${ }^{2}$, Toshiya Nakaguchi \\ Hideaki Haneishi ${ }^{2}$ and Shigeto Oda ${ }^{1}$
}

Substantial investigations on the microcirculation have highlighted the importance of the capillary refilling time (CRT), which is widely used in clinical settings [1-3]. However, CRT measurement conditions, including pressing strength and time, are inconsistent (e.g., pressing strength: light, moderate, or firm; pressing time: $3 \mathrm{~s}$, $5 \mathrm{~s}$, or until the capillary bed visually blanches) [2-5]. CRT is conventionally measured visually after manual compression, which limits the accuracy of measurement and precludes the precise determination of how long and strong the nail bed should be pressed. Therefore, we developed a novel device which can be adjusted for pressing strength and time to precisely measure CRT using an electric actuator and strength and color sensors.

CRT was measured in age- and sex-matched healthy adults $(n=31)$ using the developed device under conditions of pressing strength of $1,3,5$, and $7 \mathrm{~N}$, and a pressing time 1, 2, 3, 4, 5, and $6 \mathrm{~s}$ (Additional file 1: Methods and supplemental data).

There was a significant difference in CRT for pressing strength but not for pressing time (two-way analysis of variance (ANOVA): strength $P<0.001$, time $P=0.97$ ) (Fig. 1). There were significant differences in CRT be- tween pressing strengths of 1 and $3 \mathrm{~N}(P<0.01)$ but no significant differences among 3,5 , and $7 \mathrm{~N}(P=0.16)$. Thus, $3-7 \mathrm{~N}$ appears to be the optimal strength range for CRT measurement. A strength of $3 \mathrm{~N}$ is that which is needed to lift an object weighing $300 \mathrm{~g}$ (e.g., two smartphones) using fingers; the examinees would feel a $300-\mathrm{g}$ load on their fingers. To identify sufficient pressing time, we further analyzed the plots of the readings from the color sensor during nail bed compression. The measured values change rapidly in the initial part of compression (rapid phase) until the inflection point, where the slope of color change reduces (slow phase) (Fig. 2a). The longest period of the rapid phase was $1.999 \mathrm{~s}$ among all the study subjects (minimum $0.1022 \mathrm{~s}, 95 \% 1.149 \mathrm{~s}$ ) (Fig. 2b). The pressure release during the rapid phase may destabilize this measurement. Thus, a pressing time of $2 \mathrm{~s}$ is a good threshold to obtain stable CRT measurements for all subjects.

In the study aimed at identifying the standard pressing strength and CRT, pressing the nail bed with $3-7 \mathrm{~N}$ for $2 \mathrm{~s}$ appears to be optimal. Further development of portable CRT measurement devices fulfilling these conditions may contribute to achieving precise CRT measurements to monitor the microcirculation in clinical settings.

\footnotetext{
* Correspondence: taka.nakada@nifty.com

${ }^{1}$ Department of Emergency and Critical Care Medicine, Chiba University

Graduate School of Medicine, 1-8-1 Inohana, Chuo, Chiba 260-8677, Japan

Full list of author information is available at the end of the article
}

(c) The Author(s). 2019 Open Access This article is distributed under the terms of the Creative Commons Attribution 4.0 International License (http://creativecommons.org/licenses/by/4.0/), which permits unrestricted use, distribution, and reproduction in any medium, provided you give appropriate credit to the original author(s) and the source, provide a link to the Creative Commons license, and indicate if changes were made. The Creative Commons Public Domain Dedication waiver (http://creativecommons.org/publicdomain/zero/1.0/) applies to the data made available in this article, unless otherwise stated. 


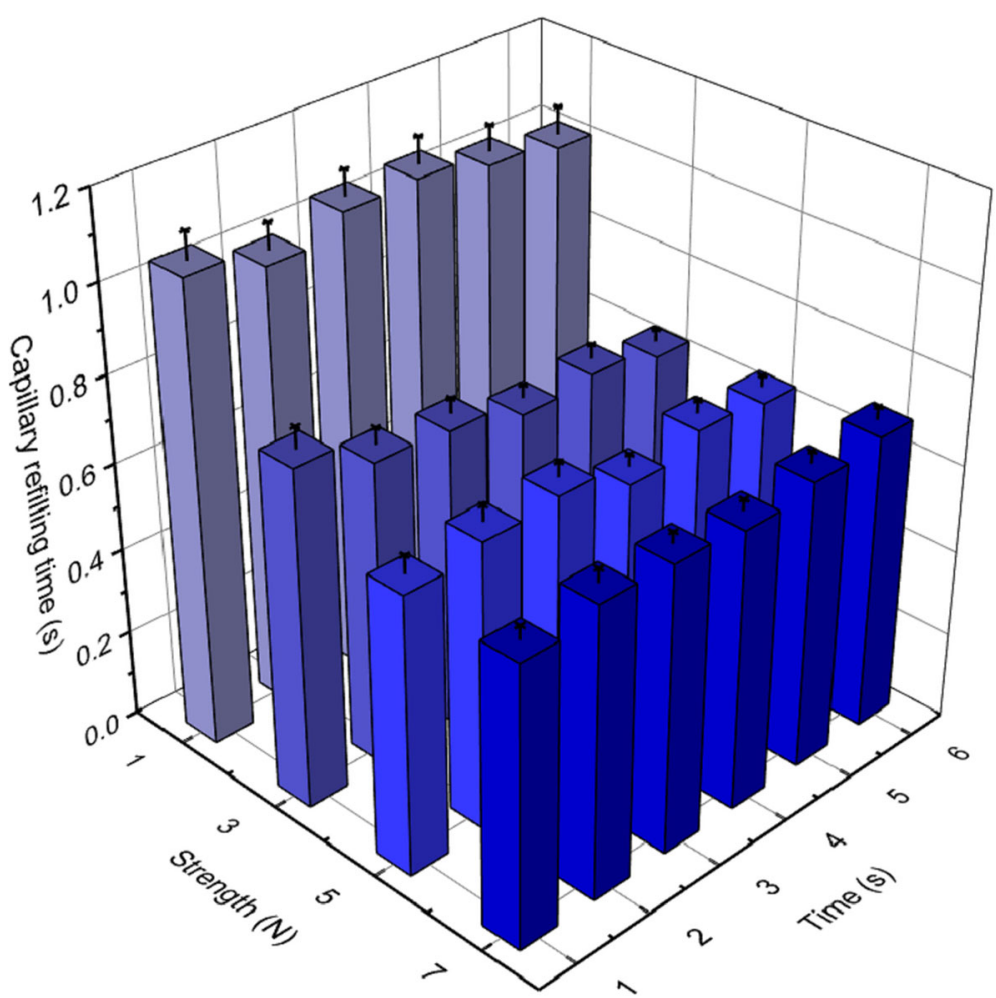

Fig. 1 Capillary refilling time (CRT). CRT was measured in 31 age- and sex-matched healthy adults under the conditions with pressing strength 1 , 3,5 , and $7 \mathrm{~N}$, and pressing time 1,2,3,4,5, and $6 \mathrm{~s}$ in technical quintuplicate. Error bars indicate standard errors
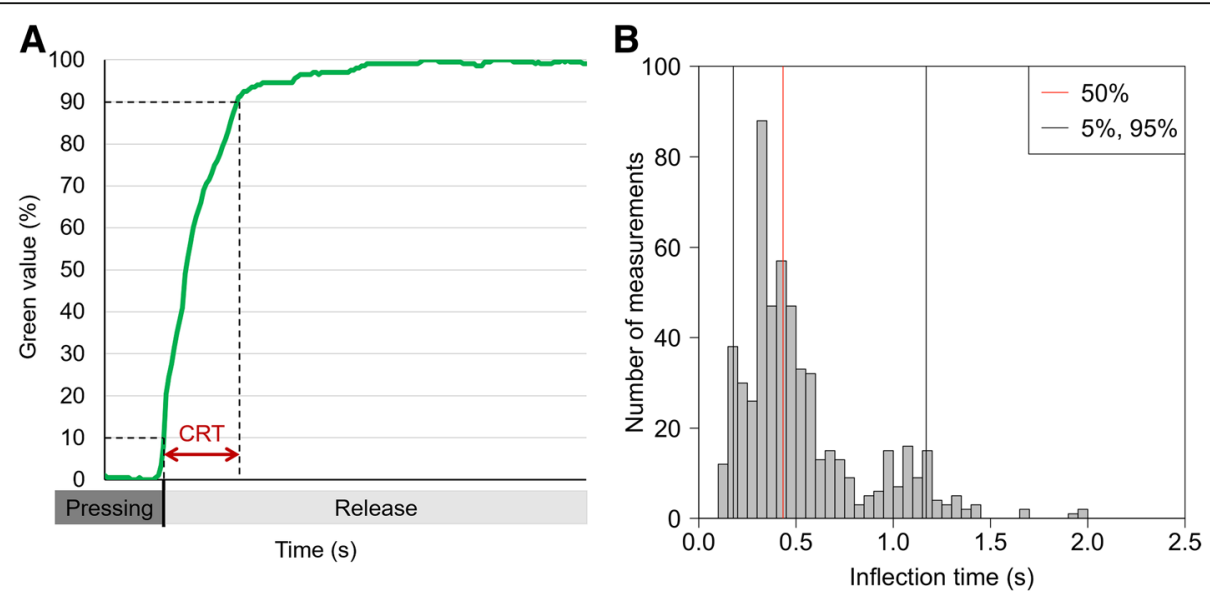

Fig. 2 Analysis on pressing time. a A schema of curve plot of the readings by the color sensor. The value sensing by color sensor rapidly changes in the initial part of the pressing nail bed (rapid phase) until the inflection point and then the slope of color change become slow (slow phase). $\mathbf{b}$ Histogram of inflection times ( $n=744$ (31 subjects $\times 24$ conditions)). Gray lines indicate $5 \%$ and $95 \%$ lines. The red line indicates $50 \%$ time line. 


\section{Additional file}

Additional file 1: Methods and supplemental data. Figure E1. Picture of developed device. The upper image is the uncovered condition to show the internal structure. The lower image is the covered condition in which we measured CRT of study subjects. 1) Stepper motor. 2) Uni-axial stage. 3) Color sensor, light source and indenter. 5) Industrial camera. 6) Emergency stop switch. 7) Cover for hiding press principle. Size $16 \mathrm{~cm} \times$ $20 \mathrm{~cm} \times 23 \mathrm{~cm}$. Figure E2. Principle of the device. Figure E3. Definition of CRT. Table E1. Characteristics of subjects and data. (DOCX 29524 kb)

\section{Acknowledgement}

We thank Mr. Yutaka Furukawa, Mr. Minami Nagano, Ms. Eriko Miyazaki, Ms. Shino Tateishi, and Ms. Ayako Teratani for helping with data collection.

\section{Funding}

This work was supported by AMED (\#JPhe1502001). The funder had no role in the study design, experiments, collection, analyses, interpretation of data, writing of the manuscript, or decision to submit the manuscript for publication.

\section{Availability of data and materials}

The datasets used and/or analyzed during our study are available from the corresponding author upon reasonable request.

\section{Authors' contributions}

RK and TN: These authors contributed to the study conceptualization and design, acquisition of data, analysis and interpretation of data, statistical analysis, and drafting and critical revision of the manuscript for important intellectual content. MS and TN: These authors contributed to developing the device, interpretation of data, and drafting and critical revision of the manuscript for important intellectual content. TO, HH, and SO: These authors contributed to the study conceptualization and critical revision of the manuscript for important intellectual content. All authors have read and approved the final manuscript.

\section{Ethics approval and consent to participate}

The study participants were informed of the experiment and agreements were obtained via consent form before the measurements. All procedures in this study were approved by the Ethical Review Board of the Chiba University Graduate School of Medicine.

\section{Consent for publication}

Written informed consent for the publication was obtained

\section{Competing interests}

The authors declare that they have no competing interests. Chiba University has filed a provisional patent application covering aspects of this manuscript. $\mathrm{TN}, \mathrm{TN}, \mathrm{HH}$, and $\mathrm{SO}$ are listed as inventors.

\section{Publisher's Note}

Springer Nature remains neutral with regard to jurisdictional claims in published maps and institutional affiliations.

\section{Author details}

'Department of Emergency and Critical Care Medicine, Chiba University Graduate School of Medicine, 1-8-1 Inohana, Chuo, Chiba 260-8677, Japan. ${ }^{2}$ Chiba University, Center for Frontier Medical Engineering, 1-33, Yayoicho, Inage, Chiba 263-8522, Japan.

Received: 26 November 2018 Accepted: 18 December 2018

Published online: 08 January 2019

\section{References}

1. De Backer D, Ospina-Tascon G, Salgado D, Favory R, Creteur J, Vincent JL. Monitoring the microcirculation in the critically ill patient: current methods and future approaches. Intensive Care Med. 2010;36:1813-25.
2. Ait-Oufella H, Bige N, Boelle PY, Pichereau C, Alves M, Bertinchamp R, Baudel JL, Galbois A, Maury E, Guidet B. Capillary refill time exploration during septic shock. Intensive Care Med. 2014;40:958-64.

3. Alegria L, Vera M, Dreyse J, Castro R, Carpio D, Henriquez C, Gajardo D, Bravo S, Araneda F, Kattan E, et al. A hypoperfusion context may aid to interpret hyperlactatemia in sepsis-3 septic shock patients: a proof-ofconcept study. Ann Intensive Care. 2017;7:29.

4. Pickard A, Karlen W, Ansermino JM. Capillary refill time: is it still a useful clinical sign? Anesth Analg. 2011;113:120-3.

5. Fleming $\mathrm{S}$, Gill P, Jones C, Taylor JA, Van den Bruel A, Heneghan C, Roberts $\mathrm{N}$, Thompson M. The diagnostic value of capillary refill time for detecting serious illness in children: a systematic review and meta-analysis. PLoS One. 2015:10:e0138155. 